\title{
Placenta accreta as a cause of peripartum hysterectomy
}

\author{
Palova E, Redecha M, Malova A, Hammerova L, Kosibova Z \\ Universal Hospital, Rimavska Sobota, Slovakia. epalova@centrum.sk
}

\begin{abstract}
BACKGROUND: Our objective was to identify the risk factors associated with placenta accreta. METHODS: Cases of peripartum hysterectomy at University Hospital of Bratislava were identified in the period from January 1st 2008 to December 31th 2013. Included were only those cases which had a histological evidence of placenta accreta.

RESULTS: Fifty patients, who underwent peripartum hysterectomy were included in the study. Between 2008 and 2013 eight cases of placenta accreta were identified. Five (62.5\%) of these were suspected before delivery. The overall incidence of PA was 0.19 per 1000 deliveries. Median gestational age at delivery was 37 weeks (range 25-41 weeks). Six of eight (75\%) women with placenta accreta had a previous caesarean delivery or curettage. In 5 patients both placenta praevia and prior Caesarean delivery were present. Among the 50 women who underwent peripartum hysterectomy, $8(16 \%)$ were patients with both prenatally diagnosed placenta praevia and previous caesarean delivery, placenta accreta was suspected in 4 of these (50\%) compared with 10 of $42(24 \%)$ without this combination of risk factors.

CONCLUSIONS: Those in whom placenta accreta was suspected were delivered earlier than 37 weeks of gestation and were less likely to have emergency delivery. Placenta accreta is the second most common indication for an emergency peripartum hysterectomy. There is a high suspicion of placenta accreta in patients with placenta praevia and after previous Caesarean section (Tab. 3, Ref. 17). Text in PDF www.elis.sk. KEY WORDS: placenta accreta, peripartum hysterectomy, Caesarean section.
\end{abstract}

\section{Introduction}

Placenta accreta (PA) is a severe obstetric complication associated with considerable maternal morbidity, such as large volume blood transfusion, peripartum hysterectomy, cystotomy, intensive care unit admission, wound infection and prolonged hospitalization $(1,2)$. PA is an abnormal invasion of chorionic villi into myometrium, with difficult separation of these two tissues after delivery. The nosologic entity is divided into three grades based on histopathology: placenta accreta, increta and percreta, because they could often not be safely distinguished from one another macroscopically (1). The exact pathogenesis of placenta accreta is unknown. The expert hypothesis includes a maldevelopment of decidua, excessive trophoblastic invasion, or a combination of both (3). Major risk factors for developing of placenta accreta include placenta praevia and prior Caesarean delivery (CS) (4). Countries with high CS incidence, such as Cyprus and Italy, are observing an increasing incidence (5). Other risk factors are maternal age (more then 35 years), multiparity, Asherman`s syndrome, smoking, chronic hypertension and history of gynecologic

Universal Hospital, Rimavska Sobota, Slovakia, and 1st Department of Gynaecology and Obstetrics, Comenius University in Bratislava, Bratislava, Slovakia

Address for correspondence: E. Palova, MD, Všeobecná nemocnica Rimavská Sobota, Srobarova 1, SK-979 01 Rimavská Sobota, Slovakia. Phone: +421.904552948 procedure (such as curretage, myomectomy, salpinectomy due to GEU) and IVF. Up to $88 \%$ of women with PA have concomitant placenta praevia $(6,7)$. PA has become the leading cause of emergency hysterectomy (8).

The reported incidence of placenta accreta is approximately $1: 1000$ deliveries, ranging from $0.04 \%$ to $0.9 \%$. The incidence of PA varies widely, mainly due to differences in diagnostic criteria of PA and characteristics of studied population (3). Recent studies estimate the maternal mortality related to PA to approximately $7 \%$ and morbidity about $60 \%$ (3). Ultrasound diagnosis of PA is sometimes possible in the first trimester by experienced sonographer (9). In the first trimester low-lying gestational sac attached to a uterine scar can be observed on ultrasound. Ultrasound characteristics during the second and third trimester are described as loss of continuity of the uterine wall, multiple vascular lacunes within placental tissue giving the "Swiss cheese" appearance to the adjacent site of placental implantation site. Other ultrasound characteristics are lack of a hypoechogenic border (myometrial zone) between the placenta and the myometrium, bulging of the placental/myometrial site into the bladder, and increased vasculature evident on color Doppler sonography. Magnetic resonance imaging (MRI) is also effective in prenatal diagnosis, and is useful in the case of inconclusive findings $(10,11)$. Elevated biochemical markers such as alpha fetoprotein and human chorionic gonadotropin within the triple screening test have been reported to be associated with an increased risk of placenta accreta (12). Women with placenta accreta usually deliver by 
a caesarean section, during which elective hysterectomy is usually performed in order to reduce maternal morbidity. Nevertheless, in recent years, more conservative management strategies are being examined to potentially minimize surgical involvement and to preserve women's fertility. The primary idea of conservative management is to leave the placenta in situ during the caesarean delivery. Conservative management is associated with a lower risk of hemorrhage and lower hysterectomy rate, but a higher risk of maternal infection (13). A retrospective, multicentric study of conservative management of placenta accreta reported a success rate of $80 \%(3)$.

\section{Materials and methods}

In our study we included patients in whom peripartum hysterectomy was carried out due to placenta accreta, at the Department of Gynecology and Obstetrics, University Hospital Bratislava, from January 1st 2008 until December 31st 2013. Medical records were reviewed for clinical history of patients especially obstetric and gynaecological anamnesis, antepartum and intrapartum management, maternal morbidity during hospitalization, neonatal admissions to intensive care unit and outcomes. Laboratory investigations and histopathological results were reviewed via the hospital database system. Diagnosis had to be based on clinical and histopathological findings of placental invasion into the myometrium. Early morbidity was defined as the occurrence of one or more of the following: maternal admission to the intensive care unit (ICU) for more than 24 hours, transfusion of $\geq 4$ units of packet red blood cells (PRBC), coagulopathy (platelets $\leq 100000$ / $\mu \mathrm{L}$, international normalized ratio $\geq 1.2$, and/or fibrinogen $\leq 200$ $\mathrm{mg} / \mathrm{dl}$ ), urinary tract injury and early re-operation. Late morbidity was defined as intra-abdominal (persistent fever, leukocytosis, abdominal pain) or wound infection. Results are expressed as raw numbers or median (range). The statistical analysis of data was performed using Student's t test, chi-square analysis and Fisher's exact test.

\section{Results}

During the studied time period there were 46102 deliveries. 50 cases of peripartum hysterectomies were performed, from which 8 patients were diagnosed with PA histologically. The overall incidence of peripartum hysterectomy during this period was $1.08 / 1000$ deliveries. The $\mathrm{PH}$ ratio increased during the study period, being 0.6/1000 in 2008 and 1.6/1000 deliveries in 2013 . The total CS rate was $37.27 \%$, with a raise from $33 \%$ (2008) to $41 \%$ (2013). The primary indications for hysterectomy were uncontrolled bleeding caused by uterine hypotony (40\%), followed by placenta praevia (20\%) and placenta accreta (16\%). The incidence of PA was 0.19 per 1000 deliveries over the 6-years period. Table 1 illustrates maternal characteristics of our study population. Table 2 describes management of women with placenta accreta. Fourteen women ( $28 \%$ ) had prenatally identifiable risk factors for placenta accreta. Five (36\%) of them underwent MRI which did not exclude PA. All women had at least one prenatal
Tab. 1. Maternal characteristics of study population.

\begin{tabular}{lcc}
\hline \multirow{2}{*}{ Maternal characteristics } & $\begin{array}{c}\text { Suspected } \\
\text { accreta }\end{array}$ & $\begin{array}{c}\text { Unsuspected } \\
\text { accreta }\end{array}$ \\
\cline { 2 - 3 }$(\mathrm{n}=14)$ & $(\mathrm{n}=36)$ \\
\hline Maternal age at delivery & $36(25-43)$ & $34(25-47)$ \\
Gravidity & $2(1-5)$ & $2(1-8)$ \\
Parity (before delivery) & $2(1-4)$ & $2(1-6)$ \\
Gestational age at delivery (weeks) & $37(27-41)$ & $39(27-41)$ \\
\hline Prior caesarean delivery & & \\
0 & $10(71)$ & $28(78)$ \\
$\geq 1$ & $4(29)$ & $8(22)$ \\
\hline Prior uterine curettage & & \\
0 & $8(57)$ & $24(67)$ \\
$\geq 1$ & $6(43)$ & $12(33)$ \\
\hline Body mass index & & \\
Less than 25 & $5(36)$ & $20(56)$ \\
$25-29.9$ & $7(50)$ & $13(36)$ \\
30 or more & $2(14)$ & $3(8)$ \\
\hline Prior uterine surgery $*$ & $3(22)$ & $4(11)$ \\
Transferred from another hospital & $1(8)$ & $4(11)$ \\
IVF & $0(0)$ & $6(17)$ \\
\hline Placental site & & \\
No praevia & $9(64)$ & $9(25)$ \\
Praevia & $5(36)$ & $27(75)$ \\
\hline
\end{tabular}

* Includes surgery for ectopic pregnancy, laparoscopic surgery. Date are given as median (range) or $\mathrm{n}(\%)$

Tab. 2. Management of women with placenta accreta.

\begin{tabular}{lcc}
\hline Management & $\begin{array}{c}\text { Suspected } \\
\text { accreta }\end{array}$ & $\begin{array}{c}\text { Unsuspected } \\
\text { accreta }\end{array}$ \\
\cline { 2 - 3 }$(\mathrm{n}=14)$ & $28(78)$ \\
\hline Mode of delivery & $10(71)$ & $8(22)$ \\
Caesarean delivery & $4(29)$ & $13(36)$ \\
Vaginal delivery & & $11(31)$ \\
\hline Indication of delivery & $7(50)$ & $4(11)$ \\
Elective caesarean section & $2(14)$ & $8(22)$ \\
Emergency caesarean section & $1(7)$ & $16(44)$ \\
Vaginal bleeding & $4(29)$ & $20(56)$ \\
Spontaneous delivery & $9(64)$ & $36(100)$ \\
\hline Anaestesia & $5(36)$ & $1(3)$ \\
General & $13(93)$ & $19(53)$ \\
Spinal & $2(25)$ & $17(47)$ \\
\hline Placental removal attempted & $10(71)$ & $21(58)$ \\
Bakri baloon tamponade & $4(29)$ & $15(42)$ \\
\hline Hysterectomy & $11(79)$ & \\
At delivery & $3(21)$ & \\
Delayed & & \\
\hline Type of hysterectomy & & \\
Total & & \\
Supracervical & & \\
\hline
\end{tabular}

ultrasound examination performed. Postpartum by the histological examination, the placenta accreta was found in 8 patients. In four cases placenta praevia with placenta accreta were present, there were two cases of placenta increta, one placenta praevia with placenta percreta and one placenta accreta. In the case of prenatal diagnosis, $64 \%$ of patients had a concomitant placenta praevia. Six of eight (75\%) women with placenta accreta had a previous caesarean delivery or curettage. 
Tab. 3. Early and late morbidity in women with prenatally suspected placenta accreta.

\begin{tabular}{lcc}
\hline Morbidity & $\begin{array}{c}\text { Suspected } \\
\text { accreta }\end{array}$ & $\begin{array}{c}\text { Unsuspected } \\
\text { accreta }\end{array}$ \\
\cline { 2 - 3 }$(\mathrm{n}=14)$ & $(\mathrm{n}=36)$ \\
\hline Estimated blood loss $(1)$ & $1,8(0,8-5)$ & $1,5(0,35-5)$ \\
\hline Maternal IUC admission & $4(29)$ & $5(14)$ \\
\hline Early re-operation & $1(7)$ & $3(8)$ \\
\hline Coagulopathy & $6(43)$ & $7(19)$ \\
\hline Blood transfusion (PRBC) & & $9(25)$ \\
$<3$ & $4(29)$ & $27(75)$ \\
$\geq 4$ & $10(71)$ & $0(11)$ \\
\hline Cystotomy & $1(7)$ & $3(8)$ \\
Ureteral injury & $1(7)$ & $3(8)$ \\
Infectious complications & $1(7)$ & $22(61)$ \\
\hline Postoperative length of stay & $11(79)$ & $11(31)$ \\
$\leq 4$ days & $2(14)$ & $30(83)$ \\
$5-8$ days & $10(71)$ & $3(8)$ \\
$\geq 9$ days & $1(7)$ & \\
\hline Early morbidity & & \\
Late morbidity & & \\
\hline Date are given as median (range) or $\mathrm{n}(\%)$ & & \\
\hline
\end{tabular}

Date are given as median (range) or $\mathrm{n}(\%)$

Of the PA cases, three women delivered vaginally (all of them had an undiagnosed placenta accreta). Five women delivered by caesarean section. Elective caesarean section was done in four patients $(80 \%)$. Emergency caesarean section was performed in 1 ( $20 \%$ ) case, at 27 th week of gestation because of intensive vaginal bleeding. From the 14 women with suspected placenta accreta, 10 (71\%) underwent hysterectomy at the time of delivery. The mean gestational age for elective caesarean deliveries among women with prenatally suspected placenta accreta was 37.75 weeks (range $37-40$ weeks). There was only one case of emergency caesarean delivery at 27 th week of gestation and this newborn required neonatal ICU admission.

Mean estimated blood loss of the PA cases was $2.35 \pm 1.1781$ (range 1000-5000). Estimated blood loss $<1,000 \mathrm{ml}$ occurred in 1 case (12.5\%); 1,000-1,999 $\mathrm{ml}$ in 1 case $(12.5 \%) ; 2,000-3,000$ $\mathrm{ml}$ in 5 cases $(62.5 \%) ; 5,000 \mathrm{ml}$ in 1 case $(12.5 \%)$. The median $\mathrm{PRBC}$ transfusion requirement was $6 \pm 2.264$ units. The amount of units of PRBC transfusions required by patients with PA is shown in Table 3. Nearly two-thirds of women with prenatally suspected placenta accreta required at least four units of PRBC transfusion. We found a nonsignificant reduction of mean blood loss of 0.500 1 , when elective hysterectomy was done compared to emergency hysterectomy $(p<0.580)$. Early morbidity in our study group was $72 \%$ (10 women). Among cases of placenta accreta there was only one ureteral injury, which occurred in women without preoperatively placed bilateral ureteric stent. This case of ureteral injury happened during elective caesarean delivery in a patient with placenta percreta. Infectious complications only occurred in one case. There was one case of placenta percreta that required reoperation within 24 hours of delivery because of intraabdominal hemorrhage. The median postoperative length of hospital stay due to PA was 6.5 (range 1-13) days. Postoperative hospital stay was longer than 7 days in $4(50 \%)$ patients with PA.
The relation between previous caesarean section and PA was as follows: 6 cases of PA were in patients without previous caesarean section, 1 in patient with history of one previous caesarean section and 1 case of patient with two previous caesarean sections. From the 50 cases of peripartum hysterectomies done in this time period, there were thirty two total abdominal hysterectomies and eighteen subtotal hysterectomies. 11 of 14 (80\%) in the group with prenatally suspected placenta accreta required total hysterectomy compared to $62.5 \%$ in group with histologically confirmed cases of PA. In group of women with prenatally suspected placenta accreta eight women (60\%) were multiparous. In women who underwent peripartum hysterectomy due to placenta accreta there were non-significantly lower rates of admission to the ICU (29 versus $14 \%$ ), large volume of blood transfusion ( 71 versus $75 \%$ ), bladder injury ( 7 versus $11 \%$ ) and intra-abdominal infection ( 7 versus $8 \%$ ) compared to women after peripartum hysterectomy for other reasons. Women with suspected placenta accreta had more frequently elective caesarean delivery than emergency caesarean delivery (50 versus 14 $\%$ ). Table 3 shows early and late morbidity for women with prenatally suspected placenta accreta. Prenatal ultrasound examination that suspected placenta accreta was verified by histological examination in significant number of cases $(p \leq 0.014)$. PA was suspected on ultrasound in 5 of 8 cases and falsely diagnosed in 9 cases. Therefore, the sensitivity, specificity, positive value, and negative predictive value was $62.5 \%, 80 \%, 35.7 \%, 91.7 \%$, respectively.

No maternal or neonatal mortality was recorded. Regarding neonatal outcomes, the median gestational age at birth was 37 weeks with a birthweight of $2950 \mathrm{~g}$. All were singleton pregnancies, 1 of them was of IVF-achieved pregnancy. Three neonates had a low birthweight of less than $2500 \mathrm{~g}$.

\section{Discussion}

The incidence of placenta accreta during the study period was $0.02 \%$; 1 case per 5000 deliveries. These findings are similar to those reported by Fitzpatrick at al., who reported incidence of placenta accreta in their establishment in 0.17 per 1000 pregnancies (14). Eller at al. reported incidence of placenta accreta in 0.83 cases per 1000 deliveries, with increasing ratio, $120 \%$ over the 12-year period (4).

We found placenta accreta to be the second most common indication for an emergency peripartum hysterectomy. Miller et al. reported placenta accreta to be the most common indication for an emergency peripartum hysterectomy (6).

The reason for increasing rate of placenta accreta is attributed to the increasing rate of caesarean births, uterine currettages and successful treatment of uterine atony with uterine drugs (15). We observed also that $75 \%$ of patients of PA in this study had a history of previous caesarean section or currettage, and $64 \%$ of patients had a concomitant placenta praevia. One published retrospective cohort study of 122 women with placenta praevia, included 25 women with PA, of which $96 \%$ had a history of previous caesarean section (16). 
Among the 50 women who underwent peripartum hysterectomy and were included in our study, 14 (28\%) women were both multigravidae and multiparous $(\geq 3)$ of which placenta accreta was suspected in 6 (43\%) women, compared to 8 of 36 (22\%) women without this combination of risk factors. These results reflect that multiparous women are more likely to have placenta accreta than primiparous. Nevertheless, of 5 (10\%) patients with both placenta praevia and prior caesarean delivery, 2 (40\%) cases had suspected placenta accreta compared with 14 of $45(27 \%)$ without this combination of risk factors. Murphy et al. reported a significant association between placenta praevia and prior caesarean section in cases of suspected placenta accreta $(93 \%)(17)$.

The incidence of placenta accreta was $0.01 \%$ in women less than 35 years old, and $0.1 \%$ in women over 35 years old. Among women with placenta praevia, which delivered during the study period, placenta accreta was verified in 5 of 156 women (3\%). Miller et al showed that placenta accreta occurred in 55 of 590 (9.3\%) women with placenta previa. They reported $2 \%$ risk of placenta praevia accreta for women younger than 35 years without previous history of caesarean section (6).

Overall, the morbidity in the group of women with suspected placenta accreta was similar to that of group of women with unsuspected placenta accreta. Major morbidity was observed in $92 \%$ of cases (33 women) in a group of unsuspected placenta accreta. Overall median estimated blood loss in cases of placenta accreta was $2,100 \mathrm{~mL}$ and median PRBC transfusion was 6 units, with a loss of $\geq 2,000 \mathrm{~mL}$ in $62.5 \%$ and a loss of $\geq 5,000$ $\mathrm{mL}$ in $12.5 \%$ of cases. Kassem et al reported a median blood loss of 2,000 $\mathrm{mL}$ and a median PRBCs transfusion requirement of 6 units in 25 patients undergoing hysterectomy for PA (16). Another study of 77 patients with PA reported median blood loss of 3,000 $\mathrm{ml}$ and median PRBCs transfusion of 5 units (18). Nearly one third of women with suspected placenta accreta in this study required admission to an ICU. These observations are consistent with the high morbidity reported in other cases of placenta accreta (4).

Gray scale ultrasonography is usually sufficient to diagnose PA, with a reported sensitivity of $83 \%$, specificity of $94 \%$, a positive predictive value of $81 \%$, and negative predictive value of $95 \%$ (16). Our data showed the sensitivity of grayscale USG $63 \%$ and specificity of $80 \%$. The reason for only $36 \%$ positive predictive value is for the small number of PA cases, with 3 undiagnosed cases in a patient without history of previous caesarean section or concomitant placenta praevia.

The median gestational age at delivery in women with suspected placenta accreta was 37 (range 27-41) weeks compared to 39 (range 27-41) weeks in a group of women after peripartum hysterectomy for other reason. Those in whom placenta accreta was suspected, delivered earlier and were multiparous $(\geq$ 3 ). Despite these facts women undergoing peripartum hysterectomy due to placenta accreta had insignificantly lower rates of early and late morbidity. Recent studies suggested that planned caesarean delivery (32th -34 th weeks of gestation) and hysterectomy at an early gestation to avoid emergency delivery may reduce maternal morbidity. If elective delivery was performed at 34 weeks of gestation then approximately $30 \%$ of emergency deliveries have been avoided. The potential maternal benefits of earlier delivery must be with agreement with the consequences of premature birth (4).

Women who underwent peripartum hysterectomy due to placenta accreta had higher rates of elective caesarean delivery (50 versus $36 \%$ ) than women after peripartum hysterectomy for other reason. Women with placenta percreta were more likely to require additional PRBC transfusion, suffer renal tract injury and require intensive care admission than women with placenta accreta or increta. One-third of women with postnatally verified placenta accreta suffered from surgical complications, mostly from urinary tract injuries. Women with unsuspected placenta accreta had an insignificant increase in early morbidity compared with women with a prenatal diagnosis of placenta accreta (83 versus $71 \%$ ). These findings are similar to those reported by Eller et al (4).

Four of fourteen (29\%) cases of suspected PA were not identified on prenatal ultrasound scan. Of the five women with suspected placenta accreta who underwent pelvic MRI, $40 \%$ (2 patients) had a false-negative study results. In our study 9 of 14 (64\%) prenatally suspected placenta accreta cases had negative pathological examination.

This study shows clearly that significant maternal morbidity is associated with placenta accreta. We included only PA cases diagnosed clinically and proved histologically. The relative rarity of PA dictated the small study size.

\section{Conclusion}

Placenta accreta is no longer a rare obstetric complication. Major risk factors include placenta praevia and previous caesarean delivery. Prenatal diagnosis of abnormal placental invasion decreases maternal and fetal morbidities and mortalities. Further studies including multiple centres and uniform diagnostic criteria are needed to identify optimal management strategies for this morbid condition.

\section{References}

1. Oyelese Y, Smulian JC. Placenta previa, placenta accreta, and vasa previa. Obstet Gynecol 2006; 107 (4): 927-941.

2. Silver RM, Landon MB, Rouse DJ et al. Maternal morbidity associated with multiple repeat cesarean deliveries. Obstet Gynecol 2006; 107 (6): 1226-1232.

3. Garmi G, Goldman S, Shalev E, Salim, R. The effects of decidual injury on the invasion potential of trophoblastic cells. Obstet Gynecol 2011; 117 (1): 55-59.

4. Eller A, Porter T, Soisson P, Silver R. Optimal management strategies for placenta accreta. BJOG 2009; 116 (5): 648-654.

5. Morlando M, Sarno L, Napolitano R, Capone A, Tessitore G, Maruotti GM, Martinelli P. Placenta accreta: incidence and risk factors in an area with a particularly high rate of cesarean section. Acta Obstet Gynecol Scand 2013; 92 (4): 457-460. 


\section{2-216}

6. Miller DA, Chollet JA, Goodwin TM. Clinical risk factors for placenta previa-placenta accreta. Amer J Obstet Gynecol 1997; 177 (1): 210-214.

7. Armstrong CA, Harding S, Matthews T, Dickinson JE. Is placenta accreta catching up with us? Austral N Zealand J Obstet Gynaecol 2004; 44 (3): 210-213.

8. Daskalakis G, Anastasakis E, Papantoniou N, Mesogitis S, Theodora M, Antsaklis A. Emergency obstetric hysterectomy. Acta Obstet Gynecol Scand 2007; 86 (2): 223-227.

9. Comstock CH. Antenatal diagnosis of placenta accreta: a review. U1trasound Obstet Gynecol 2005; 26 (1): 89-96.

10. Wong HS, Ying KC, Zuccollo J, Tait J, Pringle KC. Evaluation of sonographic diagnostic criteria for placenta accreta. J Clin Ultrasound 2008; 36 (9): 551-559.

11. Dwyer BK, Belogolovkin V, Tran L, Rao A, Carroll I, Barth R, Chitkara U. Prenatal diagnosis of placenta accreta: sonography or magnetic resonance imaging? J Ultrasound Med 2008; 27 (9): 1275-1281.

12. Hung TH, Shau WY, Hsieh CC, Chiu TH, Hsu JJ, Hsieh TT. Risk factors for placenta accreta. Obstet Gynecol 1999; 93 (4): 545-550.
13. Kayem G, Deneux-Tharaux C, Sentilhes L. PACCRETA: clinical situations at high risk of placenta ACCRETA/percreta: impact of diagnostic methods and management on maternal morbidity. Acta Obstet Gynecol Scand 2013; 92 (4): 476-482.

14. Fitzpatrick KE, Sellers S, Spark P, Kurinczuk JJ, Brocklehurst P, Knight M. Incidence and risk factors for placenta accreta/increta/percreta in the UK: a national case-control study. PLoS One 2012; 7 (12): 1-6.

15. Kwee A, Bots ML, Visser GH, Bruinse HW. Emergency peripartum hysterectomy: a prospective study in The Netherlands. Eur J Obstet Gynecol Reprod Biol 2006; 124 (2):187-192.

16. Kassem GA, Alzahrani AK. Maternal and neonatal outcomes of placenta previa and placenta accreta: three years of experience with a twoconsultant approach. Int J Womens Health 2013; 5: 803-810.

17. Murphy LA, Chasen ST. Predicting placenta accreta: which cases are undetected? Obstet Gynecol 2014; 123.

18. Wright JD, Pri-Paz S, Herzog TJ et al. Predictors of massive blood loss in women with placenta accreta. Am J Obstet Gynecol 2011; 205 (1): 38 . 